\title{
UMBERTO ECO O LA RECREACION DEL NOMINALISMO EN EL NOMBRE DE LA ROSA
}

\begin{abstract}
Alejandro Jáuregui J.
\end{abstract}
Adentrarse en el profundo contenido histórico-filosófico de esta magistral novelaensayo y en el análisis de sus formas polifacéticas, constituye un verdadero desafío, pues ya el mismo Eco ha declarado: "cada cosa que he hecho vuelve a una misma cosa: un testarudo esfuerzo por entender los mecanismos por los cuales le damos significado al mundo que nos rodea". Encierra pues, su obra una cosmovisión com pleja de su tiempo y de sus pers pectivas gnoseológicas.

En efecto, en la primera mitad del siglo XIV, escenario de la novela, se agudizan las contradicciones religiosas y políticas entre el poder espiritual y temporal, como consecuencia del derrumbe del poder feudal y el nacimiento del capitalismo. El Papa Bonifacio VIII libró descomunal batalla para apuntalar el poder espiritual y temporal del Pontificado en su famosa bula UNAM SANCTANI (1302) en un intento por salvar la "universalidad" de la Iglesia. Pero ya las mentes tenían otras perspectivas como consecuencia del gran debate universitario entre idealistas platónicos, realistas aristotélicos, conceptualistas de Pedro Abelardo y nominalis tas de Roscelino y Guillemo de Occam, que se conoce con el nombre de "lucha de universales", debate que no es un simple pasatiempo escolástico, sino el reflejo de profundos cambios sociales. Los Papas y los Humanistas se volvieron políticos, diplomáticos y analistas del proceso económico. Pero el intento de consolidación del poder papal fue rechazado por el rey Felipe IV el Hermoso, quien obligó al Papa Clemente $V$ a trasladar su sede a Aviñón. Poco después el gran humanista Marsilio de Padua, en su obra Defensor Pacis negó la "instauración divina del Papado" al reducirlo a simple acto político de los cardenales; y la Declaración de Electores Alemanes en Rense, sos tuvo que "el rey elegido no recibe el poder del Papa, sino del mismo Dios" Se adivina entonces el Absolutismo monárquico de los tiempos modemos.

Estas luchas entre el poder temporal y el espiritual habían comenzado en la "Guerra de las Investiduras" en la que se enfrentó al Papa Gregorio VII el Emperador alemán Enrique IV. Como consecuencia de esta pugna surgieron dos bloques irreconciliables: los güelfos, partidarios del Papa y los gibelinos, seguidores del Emperador.

Umberto Eco sitúa su relato en el Pontificado de Julio Santiago de Eusse de Cahors, Cardenal de Lyon, quien tomó el nombre de Juan XXII y quien gobemó la Iglesia de 1316 a 1334.

\footnotetext{
*Profesor de Latín. Universidad Pedagógica Nacional.
} 
Juan XXII, "de ciencia grande y estatura pequeña", enfrentó el desafío política, económica y espiritualmente. Como político y economista se unió a la burguesía en as censo y a los judíos, con cuyo apoyo consiguió alto poder y atesoró gigantescas riquezas. Defendió con vigor la propiedad privada contra las tendencias comunistas de los Fratriceli y enfrentó a los franciscanos. Canonizó prontamente a Tomás de Aquino y logró el respaldo de la comunidad dominicana a la que prefiró para los trabajos de la Inquisición. Implantó el toque y rezo del Ángelus y en la "Bula Sabatina" encomendó a los camelitas la devoción a la Virgen, que puntualmente rescataba los sábados muchas almas del Purgatorio. Esta devoción se hizo popularísima y trajo fuertes ingresos a clérigos y comunidades adictas al Papa.

Todo parecía ir muy bien para el Pontífice hasta cuando en uno de sus 60 mil documentos enseñó que los purgados de todo pecado no podían disfrutar de la visión beatífica hasta el juicio final. ¡Quién dijo miedo! Los alemanes con Luis de Baviera, los Fratriceli y todos los gibelinos declararon hereje al Papa y agudizaron los enfrentamientos. Quedaban reductos poderosos de seguidores del hereje Dulcino de Novara, jefe de los "apostólicos", contra quien había emprendido una cruzada el Papa Clemente V. Umberto Eco evoca magis tralmente la vida y muerte del fam oso heresiarca que organizaba ritos de desenfreno y prom is cuidad sexual.

Ludovico de Baviera se coronó autónomamente rey de los romanos y desató las iras del Papa. Era necesario buscar un acercamiento entre los bandos enfrentados y se escogió la famosa Abadía, escenario de los terribles acontecimientos que relata la novela, como lugar adecuado y neutral para las conversaciones, por estar regentada por benedictinos.

El narrador introduce progresivamente personajes históricos y ficticios y en forma magistral teje los hechos, que no son sino sombras de profundas maquinaciones ideológicas, de terribles frustraciones, de delirios místicos, de tenebrosas supersticiones y de lujuria de poder y de soberbia.

Guillemo de Basquerville y Adso de Mekl, protagonista principal y narrador-actor respectivamente, se dirigen a la Abadía, donde, más que enfrentamientos de personas, se producen choques violentos de palabras y de signos. Guillermo de Basquerville promueve una visión diferente de la vida, de la ciencia y del futuro renacimiento, inspirado en su profunda admiración por Roger Bacon y Guillemo de Occam, fuente este último del nominalismo y del agnos ticismo en que se agita vivencialmente Umberto Eco: "una manera de liberarme de viejas y múltiples obsesiones".

La Biblioteca de la Abadía será el centro enigmático de todo un proceso alienante y patético. La Abadía es patrimonio de los benedictinos, quienes la dirigen. Hijos de San Benito, fundadores de las escuelas monacales y herederos de Boecio y Casiodoro, admiradores profundos de San Agustín, quien proclama a Dios "fuente suprema de toda verdad y de toda luz intelectual". Este "neoplatonismo" pasa por Escoto Erígena, Anselmo de Aosta y llega, en destello prodigioso, a San Bue- 
naventura. Hay en la Abadía gran entendimiento entre benedictinos y franciscanos perseguidos por su lealtad al "espíritu de pobreza" de San Francisco, "el santo que más se parece a Jesucristo".

El benedictino Jorge de Burgos lleva su celo por la defensa de la verdad absoluta, (intangibilidad de las ideas en Dios) a considerar al FILOSOFO (Aristóteles) como peligroso germen del derrumbe de la Iglesia. Jorge de Burgos, el bibliotecario frustrado, el enemigo de la risa, tiene la verdad en sus manos. Cree que el Anticristo ha llegado, y que en un misterioso libro donde se encuentra La Comedia, segunda parte de la Poética de Aristóteles, es tá el peligro que acabará con el reino de Dios. Ese realismo que desnuda el ser de las cosas y la alegría de la vida, es un engendro de los demonios. Jorge ha envenenado sus folios y quien se acerque a ellos y los despegue con saliva morirá inexorablemente. Se producen varias muertes. Guillemo de Basquerville debe investigarlas pero es reemplazado en esta misión por el dominico Bernardo Gui, jefe de la delegación papal, quien descubre herejes dulcinianos camuflados de benedictinos y una "bruja" que divertía a dichos frailes y quien sedujo también a Adso de Melk, el inteligente novicio que relató los hechos para la posteridad. Pero no es la intención de estas notas contar la fábula, como diría Aristóteles, sino penetrar en el sentido de una época, como quiere el autor de El nombre de la rosa.

Al descubrirse el enigma, el libro se destruye junto con su cancerbero Jorge de Burgos, quien provocó un pavoroso incendio que arrasó la Biblioteca y con ella toda la Abadía.

Umberto Eco nos deja un interrogante profundo sobre el verdadero sentido de estos hechos en su novela-ensayo y ahora película, que conmueven actualmente al mundo. La sensación que deja la obra es de frustración y desencanto frente a las luchas religiosas medievales. La Iglesia no parece haber entendido el mensaje universal de liberación que dejó Jesucristo: el de la igualdad de los hombres, el de la verdad en libertad, el mandato del amor. Algunos papas pretendieron detentar una autoridad espiritual y temporal con artificios sofísticos, pero en realidad se movían por oscuros intereses de toda índole. La equívoca mezcla de metafísica y realismo resquebrajó las bases de la fe católica y condujo al nominalismo. Eco es demoledor al preguntar: "Entonces ¿hay que leer los libros sin recurrir a la fe, que es virtud teologal? -Quedan otras virtudes teologales: la esperanza de que lo posible sea y la caridad hacia el que ha creído de buena fe que lo posible era". (325). Y cuando se alude a la realidad, su posición nominalista es clarís ima: "De modo que sin duda la palabra "nomen" procede de "nomos", o sea ley, porque precisamente los hombres dan los nomina ad placiuun, o sea a través de una convención libre y colectiva" (364).

Esta base nominalista permite también el contundente ataque de Guillemo de Occam a las llamadas "pruebas de la existencia de Dios" al considerar que tienen un fondo equívoco y sofístico porque "dan por probado lo que intentan probar", estableciendo la fundamental diferencia entre "creer en Dios" y "conocer a Dios" (Agnosticismo). 
Umberto Eco evoca magistralmente la mezcla de lenguas en la Edad Media, en el habla de Salvatore, y traza etopeyas geniales como la de este mismo personaje al que describe así: "La cabeza rapada, pero no por penitencia sino por efecto remoto de algún eccema viscoso, la frente tan exigua que, de haber tenido algún cabello en la cabeza, éste no se hubiese distinguido del pelo de las cejas (densas y enmarañadas), los ojos redondos, de pupilas pequeñas y muy inquietas, y la mirada no se si inocente o maligna, o quizá alternando por momentos entre inocencia y malignidad. La nariz sólo podía calificarse de tal porque entre los ojos sobresalía un hueso, que tan pronto emergía del rostro como volvía a hundirse en él, transfomándose en dos únicas cavernas oscuras, enomes ventanas llenas de pelos. La boca, unida a aquellas aberturas por tina cicatriz, era grande y grosera, más ancha por la derecha que por la izquierda y, entre el labio superior, inexis tente, y el inferior, prominente y carnoso, emergían, con ritmo irregular, unos dientes negros y aguzados, como de perro" (49).

Eco disfruta y hace disfrutar el humor al evocar la ingenuidad de los simples que fácilmente adoraban reliquias insólitas: "hace tiempos vi en la catedral de Colonia el cráneo de Juan Bautista cuando tenía 12 años".

El nom inalismo y el agnosticismo de Umberto Eco palpitan en el prólogo: espero el momento de perdeme en el abismo sin fondo de la divinidad desierta y silenciosa", y en el último folio: "caeré en la divinidad silenciosa y deshabitada donde no hay obra ni imagen".

STAT ROSA PRISTINA NOMINE, NOMINA NUDA TENEMUS, "es tá en el nombre de la rosa primera, nombres desnudos tenemos". Umberto Eco nos quiere convencer de que estamos regresando a la Edad Media envueltos en nubes de palabras y más palabras: "no hay problemas de Filosofía sino de comunicación".

¿No existen realmente los valores? Y si existen... ¿Cuáles son los valores de nuestros menguados tiem pos?

\section{BIBLIOGRAFIA}

1. Eco Umberto. El nombre de la rosa. Bogotá: Círculo de lectores, 1984.

2. Scott, Sullivan, - Umberto Eco, el señor de los signas. Newsweek. 